\title{
Quando o pensamento se torna uma prática
}

BELÉM, Elisa ${ }^{1}$

\section{Resumo}

O artigo apresenta um relato da participação da autora em dois congressos internacionais, na área de artes cênicas. Os eventos ocorreram em 2012, no Reino Unido. Sendo assim, compartilham-se impressões. Descrevem-se partes das programações assistidas destacando-se a prática do debate e da reflexão, assim como a prática cênica.

Palavras-chave:

Performance; Cultura; Conferência.

\section{Abstract:}

The essay presents a report of the author's participation on two international conferences, on the field of performing arts. The events happened in 2012, in the United Kingdom. Thus, impressions are shared. Topics of the attended schedules are described emphasizing the practice of debating and thinking as well as the performance practice.

Keywords:

Performance; Culture; Conference.
1.

Mestre em Teatro (Estudos da Performance) - Royal Holloway, University of London, com o suporte do Programa ALBAN; Bacharel em Interpretação Teatral - EBA/UFMG. Doutoranda em Artes da Cena - IA/ UNICAMP, pesquisadora bolsista da FAPESP.

E-mail para contato:

elisabelem@yahoo.com.br 
Em junho de 2012, tive a oportunidade de apresentar comunicações em dois congressos internacionais, na área de artes cênicas, na Inglaterra. O conteúdo das apresentações foi parte da minha pesquisa de Doutorado em Artes da Cena, na UNICAMP2. Apresento neste artigo, um relato da minha participação nas conferências. O intuito é compartilhar essa experiência e contribuir para pensar a pesquisa em artes cênicas no Brasil.

A primeira participação foi na conferência Somatics \& Technology33, na Universidade de Chichester ${ }^{4}$, ao sul da Inglaterra, com duração de dois dias. Esta universidade oferece programas de cursos de graduação e pós-graduação em dança e em teatro. $O$ encontro reuniu profissionais das áreas de dança, teatro e performance art, que pesquisam abordagens da Educação Somática e o uso da tecnologia em cena. A programação ocorreu durante a manhã e a tarde dos dois dias do evento com comunicações, palestras, espetáculos, performances e workshops práticos. Um tema recorrente nas discussões referiu-se a projetos de dança que envolvem o uso da tecnologia e da virtualidade para gerar redes de interação ao vivo, entre performers situados em diferentes partes do mundo. No texto apresentado nessa conferência, escrevi a respeito da influência da Educação Somática e da Nova Dança no trabalho da dançarina Dudude Herrmann, desenvolvido em Minas Gerais.

O nome Educação Somática reúne abordagens do movimento como Pilates, Método Feldenkrais, Técnica de Alexander, dentre outras. A maior parte das abordagens somáticas surgiu a partir de práticas para tratar lesões para as quais a medicina tradicional não oferecia um tratamento eficaz. No entanto, o conhecimento e exercício da Educação Somática foi apropriado e também desenvolvido por dançarinos, por exemplo, por aqueles ligados à Nova Dança. Na comunicação relacionei o pensamento das práticas somáticas à noção de embodiment ${ }^{5}$ (incorporação) apresentada por Fischer-Lichte.

No segundo dia da conferência, ocorreu pela manhã, uma palestra da convidada Nancy Stark Smith - dançarina, parceira de Steve Paxton e Lisa Nelson na criação do ContatoImprovisação, em 1970. Smith é também co-fundadora do jornal de dança e improvisação Contact Quartely - a vehicle for moving ideas, além de co-dirigir as publicações da Contact Editions. Durante a tarde, Smith coordenou um evento que se repete anualmente, no solstício de verão europeu e norte-americano, nomeado como Global Underscore. Esse evento ocorre simultaneamente, em várias cidades do mundo, há dez anos. Ao iniciar e finalizar o trabalho, os dançarinos se voltam para a direção de outros países, em relação a aquele em que se encontram. O desenvolvimento do Underscore, como um
2.

A participação e viagem para os eventos só foi possível devido ao apoio da Bolsa Regular de Doutorado no País, da FAPESP.

3. http://somaticstechnologyconference2012.com

4. www.chi.ac.uk/dance; www.chi.ac.uk/ performingarts

5.

"Essa discussão como um todo aponta para as reflexões apresentadas pela teórica Erika Fischer-Litche que mostra modificações processuais na noção de embodiment, no teatro europeu. No século XVIII, o ator deveria tornar seu corpo hábil para apresentar estados psíquicos, emoções e pensamentos que caracterizavam a personagem dramática. $\mathrm{O}$ ator deveria ter a habilidade de produzir signos com seu corpo a serem decodificados pelo espectador como a um texto. Para isso, a individualidade do corpo do ator deveria ser temporariamente suspensa a fim de que mostrasse em cena um corpo da personagem. Essa noção foi modificada ao longo dos séculos. Os encenadores modernos contribuíram para a percepção de que a presença do corpo do ator já provoca por si próprio e através dos movimentos processos de afecção no espectador." (BELÉM, 2011) 
modo de trabalho com a improvisação pelo movimento, em 1990, partiu de inquietações de Smith sobre a relação entre o tempo do corpo e o tempo do relógio. A prática, em Chichester, reuniu diversos dançarinos para a improvisação seguindo um roteiro guiado por Smith, durante toda a tarde. Geralmente, o Global Underscore ocorre sem a presença de observadores, mas por ter sido realizado durante a conferência Somatics \& Technology, abriu suas portas para a presença de quem quisesse assistir ao todo ou a partes da prática. Foi muito interessante presenciar a vitalidade de Smith e também sua condução generosa do Contato-Improvisação.

A segunda apresentação foi na conferência PSI\#18 Performance Studies International ${ }^{6}$, edição dezoito. $O$ encontro desta associação de pesquisadores ocorre anualmente e é recebido por diferentes universidades no mundo. Na ocasião referida, o evento ocorreu na Universidade de Leeds, ao norte da Inglaterra, com duração de cinco dias. Esta universidade oferece cursos de graduação e pós-graduação em Performance, Cultura e Indústria. A seleção de comunicações, mesas redondas, performances e outras práticas se deu através de chamada no website da associação. A conferência contou com uma intensa programação na parte da manhã e da tarde durante todos os dias. Paralelamente, a cidade de Leeds promoveu um festival de teatro e performance nomeado como Ludus Festival.

A conferência PSI \#18 abordou o tema do curso oferecido pela universidade que a recebeu: performance, cultura e indústria. Na comunicação apresentei uma breve análise do espetáculo A Projetista, - solo de Dudude Herrmann, dirigido por Cristiane Paoli-Quito - com o intuito de discutir questões relacionadas à política pública e ao financiamento de projetos artísticos e culturais no Brasil. Para esta performance solo, a dançarina escreveu um texto no qual apresenta um discurso de tom autobiográfico, anunciando que se ocupa de escrever projetos. Ao longo da peça, elabora um projeto de espetáculo e em alguns momentos, cruza o palco para dançar. O conflito apresentado pela performer é expresso pelo desejo de dançar, pela vontade de criar, de possuir condições ideais para o desenvolvimento de sua obra ao lado da necessidade de sobrevivência, da inadequação ao sistema de subvenções do Estado e mercado de trabalho. É notória a crítica à institucionalização da arte. O espetáculo mostra uma realidade de produção que inviabiliza o pleno desenvolvimento da prática artística no Brasil.

As apresentações nas conferências foram em inglês; recorri ao recurso do vídeo para mostrar imagens de espetáculos da artista. Em ambas as conferências, as comunicações foram bem recebidas. Na primeira, pesquisadores que assistiam,

6 www.psi18.org 
destacaram a importância de que eu escreva mais a respeito da minha experiência como aluna de Dudude Herrmann, em minha tese de Doutorado. E ainda, foi feita uma associação entre a expressividade das imagens mostradas do espetáculo dessa dançarina - Sem - um colóquio sobre a falta (2007) e o trabalho da coreógrafa alemã Pina Bausch. No segundo evento, foi criticado o fato de que citei alguns nomes de dançarinos que são referências internacionais, com os quais Dudude colaborou. Pareceu aos pesquisadores presentes, que a citação tentava validar o trabalho de Dudude, sendo que foi destacado que a importância do trabalho dela deve ser considerada por si, independentemente se colaborou ou não com dançarinos estrangeiros. Discutiram-se também os modos de financiamento e produção no Brasil, bem como a existência de problemas semelhantes a aqueles levantados, em outros países. Foi enfatizado que o Brasil deve pensar modos de financiamento sem basear-se em possíveis modelos internacionais a fim de não dar continuidade ao modelo de relação colonizador/colonizado.

A programação da conferência em Leeds também apresentou diversas formas de trabalho: palestras, comunicações, grupos de investigação prática e teórica, além de performances. As palestras tiveram duração aproximada de 30 a 40 minutos para cada convidado. Já as comunicações reuniram tanto professores e pesquisadores consolidados, quanto estudantes de Doutorado ou, conforme são chamados na Inglaterra, candidatos ao título de Doutor. Essas comunicações foram em todos os casos, apresentadas como leituras de artigos, com duração de 20 minutos. O formato da apresentação das comunicações, mesmo sendo tradicional - a leitura, com o raro uso de recursos como Power Point e vídeos - poderia parecer pouco funcional. No entanto, mostrou-se bastante rico, já que a escuta conduzia ao debate dos artigos, fazendo com que o pesquisador fosse confrontado com opiniões e questões a serem mais investigadas ou mesmo, tendo sua proposta valorizada por aqueles que se propunham a dialogar. Além disso, quem assistia passava a se relacionar com uma série de conteúdos que podiam contribuir para sua pesquisa individual como professor ou criador. Osgruposdeinvestigaçãopráticapropuseramdesdetreinamentos até espetáculos que foram acompanhados de breve exposição teórica ou conceitual e discussão. Ocorreu ainda, uma mesa que reuniu diversos editores de livros e revistas acadêmicas e não acadêmicas que puderam trocar informações e questões a respeito do formato, conteúdo, suporte, público alvo e financiamento para publicações.

Ao final, a experiência de seguir as duas conferências e,
Destaco o trabalho da The Live Art Development Agency, que além de realizar publicações, disponibiliza 5000 títulos, DVDs e jornais para consulta, em uma sala de estudos em Londres. 
principalmente, a última, correspondeu, para mim, à participação em um curso intensivo, no qual pude presenciar diversas formas de pesquisa, bem como seus conteúdos. Assisti a uma pequena parcela dentro da vasta gama de atividades. A tendência geral das pesquisas apresentadas mostrou relações estabelecidas entre um objeto e a sociedade ou a cultura. O discurso individual era construído através da análise crítica. A referência a autores não pressupunha a aplicação direta de um conceito específico, mas o diálogo entre a obra de um ou mais autores e o ponto de vista crítico apresentado pelo artigo. Notei que havia uma ligação muito próxima entre a prática artística e o ato de pensar esta prática, de forma que apresentações de performances e espetáculos, por exemplo, incluíam a discussão e a análise. $O$ ato de refletir e pensar tornava-se aos poucos, um modo de prática. Não havia pudores nem omissões após ouvir uma comunicação - a discussão era imediata; eram levantadas questões, contrapostos pontos de vista. O discurso era sofisticado, no sentido de valorizar a importância daquela pesquisa para o autor. Valorizou-se a percepção das implicações e ressonâncias que a pesquisa tinha em relação à experiência prática ou à reflexão teórica do pesquisador, bem como o apontamento crítico sobre a sociedade. A profundidade das discussões se encontrava justamente no aspecto político, entendendo essa palavra como o cerne do social, como a atitude e o comportamento humano, sendo assim, um aspecto ético das pesquisas.

Um dos primeiros painéis de comunicações que assisti, por exemplo, era nomeado como Performing humanity (conflict/ healing through performance), que pode ser traduzido como: "Ações humanitárias (conflito/ cura através da performance)". Em uma das comunicações, um pesquisador defendeu a ideia de que os governantes norte-americanos e britânicos evitam intencionalmente o uso da palavra "genocídio". A partir de conceitos relacionados à performatividade, o pesquisador expôs a construção do discurso desses governantes para evitarem assumir compromissos em relação a possíveis assassinatos em massa. Mesmo que a comunicação pudesse ser apresentada em conferências de outras áreas, discutiu questões relacionadas à performance.

Já em outro painel, assisti a uma análise de um trabalho do performer de origem britânico-alemã Tino Sehgal ${ }^{8}$, que nomeia suas performances como "situações construídas". Coincidentemente, tive a oportunidade de assistir a um de seus trabalhos em 2005, na Bienal de Veneza, nomeado como This is so contemporary. Os visitantes entravam em uma sala de exposição na qual não havia nenhuma obra a ser vista. Em cada ponto da sala, havia um guarda uniformizado como se
"What all of Sehgal's works have in common is that they reside only in the space and time they occupy, and in the memory of the work and its reception. The artist himself describes his works as 'constructed situations', whose materials are the human voice, language, movement, and interaction, without the production of physical objects. His pieces are choreographies that are regularly staged in museums or galleries, and continuously executed for the entire duration of a show. The reaction or even participation of the spectator gives the possibility for the work to actually happen. The artwork is the constructed situation which arises between the audience and the interpreters of the piece. Afterwards, the work of art will exist only in the world of experience and memory of those who directly experienced it." (Wikipedia) 
estivesse vigiando as obras inexistentes e os visitantes. De repente, os guardas iniciavam uma breve coreografia descontraindo de suas posturas e dizendo em voz alta: "Oh, this is so contemporary, contemporary, contemporary." "“Ah, isto é tão contemporâneo, contemporâneo, contemporâneo"). As outras performances do artista parecem seguir o mesmo espírito. Através da comunicação referida, a pesquisadora, de origem turca, apresentou sua experiência como participante contratada para uma das performances de Sehgal.

Em outro painel, assisti a uma análise de performances da artista Marina Abramovic comparando-as a performances norte-americanas. Em seguida, outra comunicação mostrou a apropriação de performances de Abramovic por seriados norte-americanos como Sex and the City, que parodiam algumas de suas obras em determinados episódios.

Em um grupo prático, participei de duas aulas - uma da abordagem de Educação Somática "Método Feldenkrais"" e outra de Yoga. A primeira foi conduzida pela Dra. Libby Worth, da Royal Holloway, University of London, que foi a orientadora da minha dissertação de Mestrado. Após os exercícios, foi apresentado o contexto de vida de Moshe Feldenkrais e suas principais proposições a fim de debater a aplicação dessa abordagem ao treinamento do ator. Worth apresentou possíveis conexões entre a vida de Feldenkrais e sua prática, que foi desenvolvida em seu próprio corpo machucado. Para essa Professora, o Método Feldenkrais enfatiza o aprendizado experimental e individual. Dessa forma, é preciso que seja construído um ambiente para aprendizagem na qual se evita a cópia do movimento e se ensina a fazer menos esforço para que, aos poucos, sejam notadas pequenas mudanças. Esta questão do auto-ensino foi enfatizada como importante para pensar a respeito do treinamento em atuação e também como uma abertura para explorar o self. Por ser uma Professora de Ensino Superior em Teatro na Royal Holloway, Worth apontou que os cursos de graduação não treinam estudantes, já que não há tempo hábil. Além disso, destacou a complexidade de transmitir mecanismos de treinamento em atuação, como por exemplo, aqueles propostos por Stanislavski e que foram na verdade, recriados nos Estados Unidos da América pelo Actor's Studio e divulgados pelo mundo. A aula de Yoga Ivengar expôs também o contexto de seu desenvolvimento e questões em torno do aprendizado da prática hoje em dia. Perguntou-se como utilizar tais exercícios para a prática criativa.

No dia seguinte a esses treinamentos, que foram os últimos de uma série realizada por esse Grupo de Trabalho na Conferência, os pesquisadores participantes se reuniram em
9.

"The Feldenkrais Method employs Awareness through MovementTM (ATM) and Functional Integration ${ }^{\mathrm{TM}}$ (FI) as means of enabling the individual to experience the transformative miracle of efficient, integrated and aesthetically pleasing movement. (...) Functional Integration is a hands-on approach that enables the practitioner to use his physical organisation and experience to guide the student to discoveries. In Functional Integration, lessons are bespoke and are selected by the practitioner to address the individual's movement habits and physical organisation. Awareness through Movement, on the other hand, is usually experienced through group lessons that involve verbal instructions in that exploratory journey to a more efficient and functional use of the whole self in movement." (IGWEONU, 2010, p. 11 e 12) 
uma mesa de discussões. Foram relacionados pontos-chave nos debates a serem continuados por esse Grupo. Reproduzo esses pontos conforme minhas anotações pessoais: Quais são as ferramentas teóricas necessárias para uma análise cultural do treinamento? Como os métodos de treinamento diretos e indiretos se inter-relacionam? Como a ponte do treinamento para a performance é administrada? Em qual extensão o ensino de uma prática de treinamento alcança a pedagogia ou o seu ensino original? Como e quando a análise cultural inspira o ensino na sala de aula? Que papel a imaginação realiza na incorporação de ideias conceituais?

Algumas palestras e comunicações tiveram como tema o método de ensino e proposições de determinadas escolas ou cursos. Destaco as comunicações dos professores da Norwegian Theatre Academy (Ostfold University College) ${ }^{10}$, Oslo, que oferece dois programas de graduação: um em atuação e o outro em cenografia. Nesses programas, sessenta por cento dos professores são artistas visitantes recrutados em todo o mundo; os cursos são oferecidos em inglês e não há taxas de matrículas. O encenador norte-americano Robert Wilson é um dos artistas curadores dos programas da escola. Em uma dessas comunicações, por exemplo, a pesquisadora e Professora Karmenlara Ely partiu da questão: Como treinamos um ator? A Professora defendeu que o ator é alguém que está se tornando mais consciente e não alguém preparado para fazer algo. Assim, desenvolveu sua palestra trazendo alguns conceitos relacionados à performatividade e à noção de self ${ }^{11}$, conforme apresentada por Philip Auslander no artigo Just be your self. Para essa Professora, a escola ao invés de oferecer uma coleção de técnicas para os estudantes, deveria estimular o diálogo com a experiência da escuta. Assim, remover a técnica e criar espaço para a presença junto ao outro, desenvolvendo a percepção.

Outro ponto muito rico do encontro foi a pluralidade das abordagens e a reunião de pesquisadores dos mais diversos países para debater, conversar, trocar. O encontro foi prazeroso e houve um real espaço para interlocução, sem qualquer tentativa de expor eventuais supremacias ou disputas em torno do conhecimento. Mas é claro, que a pluralidade foi transpassada pelo fator econômico. Mesmo havendo participantes do Brasil e conferencistas da Colômbia e Índia, a participação majoritária foi de britânicos, norte-americanos, neozelandeses, japoneses e canadenses. A questão da integração internacional é também sociopolítica, portanto. Parece haver um grande interesse pela cena latino-americana e brasileira, apesar do pouco número de trabalhos submetidos ou aceitos de pessoas dessas origens. Há um estímulo também para pensar a cena latino-
10.

www.hiof.no/scenekunst; scenekunst@hiof.no
11.

"The problematic of self is, of course, central to performance theory. Theorists as diverse as Stanislavski, Brecht, and Grotowski all implicitly designate the actor's self as the logos of performance; all assume that the actor's self precedes and grounds her performance and that it is the presence of this self in performance that provides the audience with acess to human truths. Their theories are aptly summarized by a sentence of Joseph Chaikin: "Acting is a demonstration of self with or without a disguise"(1972:2)." (AUSLANDER, 1997, p. 30) 
-americana por ela mesma, sem a referência tão direta ou a comparação com a cena europeia e norte-americana. Isso é feito no intuito de valorizar a diferença cultural para perceber como a cena tem um pensamento e organização particular.

Creio que com o aumento do número de cursos de graduação e pós-graduação em Teatro, Dança e Artes Cênicas no Brasil, a qualificação profissional aumente. O intercâmbio intercultural contribuirá para o desenvolvimento e divulgação das pesquisas na área. É importante que a cena brasileira seja mostrada e as discussões transbordem fronteiras e cresçam a partir da diferença. As conferências internacionais podem ser um ótimo meio para fomentar a troca. 
AUSLANDER, Philip. Just be your self - Logocentrism and différance in performance theory. From Acting to Performance - essays in modernism and postmodernism. London: Routledge, 1997.

BELÉM, Elisa. A noção de embodiment e questões sobre atuação. Revista Sala Preta - PPGAC, ECA/USP, São Paulo, v.1, n.11, 2011. Disponível em: <http://www.revistasalapreta. com.br>. Acesso em: 24/04/2012.

IGWEONU, Kene. Feldenkrais Method in Performer Training Encouraging Curiosity and Experimentation. Swansea: CiPPE (Swansea Metropolitan University), 2010.

MARSEN, Sky. Becoming More Than Human: Technology and the Post-Human Condition - Introduction. Journal of Evolution and Technology.vol.19, n.1, set. 2008. Disponívelem: <http://jetpress.or/v19/marsen.htm>. Acesso em: 22/08/2012. 